\title{
Exploration and Practice of Practical Training for Undergraduates Majoring in Life Sciences Specialty in Agricultural Universities and Colleges
}

\author{
Xia Yuejun, Tao Chenlu, Liu Xiuming, Yang Guangshun, Li Haiyan \\ Jilin Agricultural University, Changchun, 130118, Jilin
}

Keywords: Agricultural colleges and universities, Practical training for undergraduates majoring in life sciences specialty, Exploration and practice.

\begin{abstract}
Practical training is one important education reform measure and the innovation of talent training mode for agricultural colleges and universities. In this paper, it discusses the importance of practical training for undergraduates majoring in life sciences specialty in agricultural college and university, besides, according to the college or university situation, disciplines and specialty features and undergraduates' actual exploration, the 'one, two, three, four, five' mode for undergraduates has been established and it has certain reference significance and promotion value.
\end{abstract}

\section{Introduction}

Practical training refers to the teaching process of training students in their vocational and technical applications ability according to the talents training rules and objectives under the control of colleges and universities ${ }^{[1]}$. The practical training of life sciences specialty refers to undergraduates' engaging in the study, research and secondment practice in research platforms and enterprises by using their acquired knowledge and skills, under the leading of school organization as well as the guidance and assistance of teachers so that to help students improve their ability and quality. In 2010, Jilin Agricultural University takes the practical training as an important education reform measure and through providing students in different needs with the chance of direct participation in scientific research projects and enterprises secondment practice, guides students to the scientific research frontier and enterprise's first production line, so as to cultivate the scientific research quality, enlighten the innovation consciousness and improve practical ability. Up to now, our school has been carrying out the practical training for nearly seven years and according to the statistics, the undergraduates participating in the practical training have published more than 100 academic papers and have got more than 120 national or provincial innovation and entrepreneurship awards, besides, the proportion of postgraduate students has increased from $25 \%$ to $33 \%$.

\section{Importance of Practical Training for Undergraduates Majoring in Life Sciences Specialty in Agricultural Universities and Colleges}

The education of the students majoring in life sciences specialty of Agricultural colleges and universities should include the combination of knowledge imparting and exploration, the benign interaction between teachers and students, and achieve that teaching benefits teachers as well as students, besides, take the mobilizing of students' autonomous learning, stimulating of students' curiosity and creativity as the teaching goal ${ }^{[2]}$. Practical training is carried out based on the national scientific research platform of the school and a large number of high-grade, high-precision, advanced modern experimental instruments provide a stage for students to improve their innovation ability. Regular holding of frontier academic lectures in the training has built rich academic and innovation atmosphere, which is helpful for students to understand the cutting-edge knowledge, be familiar with the industry development potential and gradually improve the students' exploring consciousness and curiosity. In the practical training, hosting the experimental subject design 
competition and innovative experiment competition etc. regularly, will motivate students to study independently and improve students' creativity.

Life sciences is the discipline based on experiment. The professional quality requirement of the talents cultivated by this discipline is solid basic theoretical knowledge and great experimental practical ability. At present, with the increasing number of college students, the employment issue has become the issue of common concern for universities and enterprises, on the one hand, the lack of certain abilities for talents cultivated by colleges and universities has made them face the situation that 'difficult to find one job', while the enterprises face the situation that 'difficult to find one high-ability employee', which kind of awkward situation not only shows that the enterprises and the universities have not realized the real seamless connection, but also highlights that the undergraduates lack the skilled ability for employment. The practical training of life sciences is not simply solving the problem of undergraduates' employment, but cultivating their ability of transforming the innovative idea into value-creation capacity, and then forming the competitiveness of differentiated employment. The practical training of life sciences, by sticking closely to the demand of social shortage of the professional personnel, makes the custom-made practical training system, carries out the practical training type of cultivation, besides, connects the learning and application based on the rule of 'set according to demand', finally achieves the 'seamless connection' of education and employment.

Practical training is the effective attempt of deepening the agricultural life sciences talents cultivating mode reform under the guidance of hierarchical classification.

The life sciences specialty has the typical characteristics of big discipline span and strong comprehensiveness. The life sciences takes the trial implementation of classified cultivation, which is not only the inevitable choice of higher education teaching reform under the new situation, but also the beneficial attempt to realize the individualized teaching, meet the demand of students' personality development and social multi-talents development, finally achieve the dual benefit of teaching and learning ${ }^{[3]}$. The practical training follows the concept of 'people-oriented, design-to-demand, platform-building, classified cultivation, respective development', adopts the cultivation method 'combination of production, study and research', follows the principle of 'laying a solid foundation in lower-grade period and adopting distributary and classified cultivation in higher-grade period' and builds flexible course system of 'basic platform + direction module' , besides, under the support of faculty condition, practical teaching condition and institutional condition, it is necessary to gradually establish the talent training mechanism, which adapts to the development trend of application-oriented and research-oriented higher education so that to promote the healthy and sustainable development of life sciences specialty talents cultivation in agricultural colleges and universities.

\section{Exploration and Practice of Practical Training for Undergraduates Majoring in Life Sciences Specialty in Our University}

Based on the cultivation of talents for all-round development, highlighting the cultivation of innovative talents and focusing on cultivating applied talents' is the requirement of The Outline of the National Medium and Long-term Plan for Talents Development (2010-2020), meanwhile, it is also the inevitable trend for colleges and universities to deepen the education and teaching reform, based on which, in 2010, our university, according to the university situation, students situation and the characteristics of the disciplines as well as following the law of higher education and the characteristics of undergraduates growth, has explored and established the '12345' (one center, two directions, three levels, four platforms, five combinations) mode for undergraduates majoring in life sciences specialty.

Practical training centers on cultivating scientific research quality, inspiring innovation consciousness and improving practical ability. The practical training is divided into two directions. For the innovative direction, by setting up the undergraduate science and technology innovation subject, participating in teacher's topic research and holding science and technology forum for undergraduates etc. to let more students to participate in scientific and technological innovation and 
build the atmosphere of innovative talent training. For the employment guidance, through carrying out the intradisciplinary instrumentation practical training and enterprises' in-post practical training to make the professional theory and application practice get well combination, besides, improve the students' professional ability and professional quality.The practical training is divided into three levels as well as into vertical and horizontal. The three aspects in vertical refer to that focus on the science popularization education during freshman year, focus on innovation guidance during sophomore year and focus on employment and entrepreneurship support during the junior year. Take hierarchical practical training horizontally and in terms of the students who are hungry for knowledge, they should take the innovation as the central guiding, besides, under the guidance of experts and scholars carry on the study of big subject, which purpose is to cultivate the tip-top talent of life sciences; For the ordinary undergraduates, they should take the popularization of science as the central guiding, besides, make use of all kinds of science and technology competitions, academic reports and varieties of entrepreneurial activities etc. forms to attach importance to, inspire and guide the students' psychology in interest, winning and knowledge, besides, encourage students to give full play to their strengths and personalities and step from textbook to practice, from class to society so that to lay a solid foundation for the standout of application-oriented talents; For the students who are difficult to digest the knowledge, they should take the practical skill practice as center to improve their employment quality. The practical training depends on four platforms: undergraduates' innovation base in school, national scientific research platform in school, enterprises' secondment practice platform, employment and entrepreneurship ability developing base in school.

The practical is based on the organic combination with classroom teaching, science and technology innovation, discipline competition, social practice, employment and entrepreneurship.

First, combine the practical training and classroom teaching. Classroom teaching and extra-curricular practical training have become the closely related two links in the whole teaching process of life sciences specialty and the two links promote each other and complement each other. Students acquire the knowledge and skills in the classroom and obtain rich and vivid representations during the practical training process, thus deepen their understanding of the knowledge in the classroom, which stimulates students' enthusiasm in learn, arouses students' interest in seeking knowledge and motivates students' desire to learn knowledge.

Second, combine practical training with scientific and technological innovation activities. The research of subject project is an important measure for the improvement of undergraduate's scientific and technological innovation ability and quality cultivation and it can continuously promote the extension of the first classroom. In the course of practical training, organize the students to participate in the teachers' scientific research projects and the national, provincial, municipal and undergraduates' scientific and technological innovation project activities. At present, in the field of subject specialty, a good innovation atmosphere 'students' independent determination of subject, teachers' subject with the students' help, subject research focusing on practice' has been established.

Third, combine the practical training and subject competition. The undergraduates' subject competition is the important carrier of innovative talent cultivation and it has an irreplaceable role in cultivating undergraduate's innovation ability. After several years of exploration and practice, the mode of undergraduate's innovative team construction and subject competition team cultivation 'team of interest-- team of practical training project -- team of competition' has formed.

Forth, combine practical training and social practice. Through setting up the enterprise's practical training platform, make students learn about the society in advance and master the skills in practice skillfully, which has broadened the channels for the 'zero distance' connection between students and enterprises.

Fifth, combine practical training with the promotion of undergraduate's employment. Through carrying out the practical type of cultivation, stick closely to the demand of social shortage of the professional talents in life sciences and makes the custom-made practical training system, besides, connects the learning and application closely based on the rule of 'set according to demand', which 
has created the unique development mode for cultivating applied talents in the same kind of colleges and universities.

Strong entrepreneurial atmosphere and double-augmented entrepreneurs quantity. Only in 2015 and 2016, the number of graduating students who have chosen the self-employment has reached 25, which accounts for $5 \%$ of the total number of graduates in this specialty, and it has gradually converged into one demonstration group of entrepreneurship driving employment.

Undergraduate students are independent in or participate in the national '863' project, national natural fund, national transgenic major special projects, provincial key projects and college or university projects in total number of 44 and the number of participants reach 202. In seven years, 30 works have been awarded( provincial level and national level) in the 'Challenge Cup' competition, Internet Plus competition. In the China College Students' Innovation and Entrepreneurship Competition, Life Sciences Innovation Experiment Competition of Jilin Province etc. other disciplines competitions, 90 provincial and national awards have been issued. The students who have participated in the practical training have published 102 academic papers.

In 7 years, among the 640 undergraduates, who have participated in the practical training, 460 students have achieved the 100\% counterpart employment and 180 students have obtained the master degree. The practical training center has been awarded the honorary title of National Energize League General Branch, Jilin College Excellent Innovation Student Organization etc.

People-oriented, innovative talent cultivation mode. Whether one university can get sustainable development depends on whether its talent training reflects its characteristics and whether it has core competitiveness ${ }^{[4]}$. At present, the employment situation of college students is becoming more and more serious and is becoming the focus of universal attention. The fundamental way to solve the situation of undergraduates' employment difficulties is to establish the 'students-oriented' concept, change the pattern and mechanism of talent cultivation, besides, the colleges and universities should take the initiative to adapt to the new situation and be brave to try the teaching reform as well as boldly innovate the talent training system based on the national conditions, provincial conditions, college and university conditions, specialty characteristics and students' practical conditions, so that to improve the undergraduates' comprehensive quality and core competitiveness and cultivate high-quality talents for economic and social development.

Based on the classified training, mobilize undergraduates' enthusiasm in learning professional knowledge and firm undergraduates' confidence in becoming a useful person. With the popularization of higher education, college and university students are of variable quality, which requires the college and university to improve the structure of talents training, cultivate students' innovation, entrepreneurship and practical ability and comprehensively improve the quality of talents training. Each discipline and specialty of college and university should play the role of bridgehead in the reform and practice of classified cultivation, besides, combined with the actual work, fully combine the books and practice, combine inheritance and innovation and combine the hope of the Party and the country with undergraduates' individual growth need, furthermore, follow the rules of education and talent growth and explore various ways to promote the cultivation of talents. Fully mobilize the enthusiasm of college students to learn professional knowledge and firm undergraduates' confidence in improving themselves and becoming a useful person.

Establish the typical and promote the benign development of undergraduates' classified cultivation. Under the attention, support and care of the colleges and universities, the practical training has given full play to the external and external links of talents cultivating, the interaction between the first and second classroom, the integration of curricular and extra-curricular content and the connection of education and employment, besides, the individualized talents cultivation mode with the characteristics of life sciences specialty in agricultural colleges and universities can solve the difficult problem of talent cultivation for undergraduates majoring in life sciences specialty, increase the quality of talents cultivating, promote undergraduates' entrepreneurship and employment and realize their lifelong development.

Through the nearly seven-year of practice, the new way of professional talent training for the life sciences specialty of agricultural colleges and universities in the new period has been obtained, and 
it has got application and popularization in colleges and universities, furthermore, it has achieved good results. The implementation of this teaching reform not only has achieved the goal of cultivating talents that the economic and social development requires, but also has made the teacher get full exercise and improvement, which has laid a solid foundation for talent cultivating.

\section{Acknowledgements}

1 The planned project of Social Science Research in the 12th Five-Year Plan organized by the Education Department of Jilin Province-Study of the Employability Training Mode for Undergraduate in Agricultural Colleges and Universities Based on Career Development(Words Introduced by Jilin Educational, Scientific and Cultural Organization, No. 151 [2016])

2 Subject of Higher Education and Teaching Study of Jilin Province-Study and Practice of S cience and Technology Activity Practical Training Class for Undergraduates Majoring in Biological Science Related Specialties

\section{References}

[1] Zhou Lianqi, Zhang Shuya, Adhere to the Road of Integrating Production, Learning and Research, Improve the Construction and Operation Management of Practical Training Base[J].Journal of Tianjin Vocational Institutes, 2006, (3).

[2] Liu Zhiyun, Study of the Relation Between Research-based Teaching and Research-based Learning [J]. China University Teaching, 2006,(2).

[3] Liu Zhiyun, Study of the Relation Between Research-based Teaching and Research-based Learning [J]. China University Teaching, 2006,(2).

[4] Wang Jianli. Establishing of Modern University Concept, School-running Direction of Sticking to Serving Society[J]. China Higher Education Research, 2003,(7). 